\title{
Erratum to: Effects of methylphenidate on attention in Wistar rats treated with the neurotoxin $N$-(2-chloroethyl)- $N$-ethyl-2- bromobenzylamine (DSP4)
}

\author{
Joachim Hauser ${ }^{1} \cdot$ Andreas Reissmann $^{1}$ - Thomas-A. Sontag ${ }^{1} \cdot$ Oliver Tucha $^{2}$. \\ Klaus W. Lange ${ }^{1}$
}

Published online: 7 August 2017

(C) Springer-Verlag GmbH Austria 2017

\section{Erratum to: J Neural Transm (2017) 124:643-654 DOI 10.1007/s00702-017-1679-x}

The present study is a part of a large research project investigating the effects of substances used in the treatment of attention deficit hyperactivity disorder on attention in rats. This paper presents the results for methylphenidate in DSP4-treated rats while our findings regarding atomoxetine were published later (Hauser et al. 2017). This reference was not included in the present paper due to the close succession of the two articles' publication.

Hauser J, Reissmann A, Sontag TA, Tucha O, Lange KW (2017) Effects of atomoxetine on attention in Wistar rats treated with the neurotoxin $N$-(2-chloroethyl)- $N$-ethyl-2bromobenzylamine (DSP4). ADHD Atten Deficit Hyperact Disord. doi:10.1007/s12402-017-0225-x (published online first: 14 March 2017)

The online version of the original article can be found under doi:10.1007/s00702-017-1679-x.

Joachim Hauser

Joachim.Hauser@psychologie.uni-regensburg.de

Klaus W. Lange

Klaus.Lange@ur.de

1 Department of Experimental Psychology, University of Regensburg, 93040 Regensburg, Germany

2 Department of Clinical and Developmental Neuropsychology, University of Groningen, Groningen, The Netherlands 